\section{END MILLING OF Ti-6AI-4V} ALLOY BY PCD INSERTS
WITH LASER-MACHINED
INTEGRAL CHIPBREAKER

\author{
TOMAS TRCKA, JAKUB PALOVCIK, \\ ALES POLZER, FRANTISEK SOUKAL
}

Brno University of Technology, Faculty of Mechanical Engineering, Institute of Manufacturing Technology, Brno, Czech Republic

DOI: 10.17973/MMSJ.2019_10_2018130 e-mail: 153306@vutbr.cz

Polycrystalline diamond (PCD) is becoming more available cutting material due to developing technologies, but it is still one of the difficult-to-cut materials. Nowadays, sharpening of diamond inserts is usually performed using unconventional machining methods, where the high hardness of the material is not a deciding factor. Apart from electrical technology (WEDM or EDM-G), PCD is also sharpened by laser technology. The production of integral chipbreaker on the rake face of the PCD insert is an advantage of laser technology, in comparison with other technologies. In this research, three types of chipbreakers were designed and used in a real machining process. This was carried out on the workpiece material Ti-6Al-4V alloy, which is generally used in the transport industries and medicine, but still presents great challenges in its machining. Influence of the individual types of integral chipbreakers compared also to the normal PCD insert, which had a polished rake plane, was investigated. This was based on the force loading and the integrity of the machined surface. Wear of the inserts, images from electron microscope were also included in the analysis.

KEYWORDS laser technology, chipbreaker, Ti-6Al-4V, PCD, end milling, force loading.

\section{INTRODUCTION}

Machining, precisely material cutting, is one of the most commonly used techniques for producing various components. However, it is necessary to meet a set of complex operating conditions for the successful realization of machining. As a successful machining could regard - production of good quality, functional and precision component in the required time with minimal production cost and at the same time today's trend, which is the maximum environmental care. Thus, progressive machining is the elimination of process fluids. Complex issue involves a lot of variables and requires knowledge of the process itself respecting the interaction of the whole machinetool-workpiece system. Machined surface parameters are the priority output of the process and the target response. From this point of view, the problem of the identified chip formation mechanism is of high importance.

When the tool edge penetrates the machined material, elastic and consequently plastic deformations of the workpiece material occur in three zones [Shokrani 2012]:

- in front of the tool edge (the primary plastic deformation zone),
- on the rake face of the tool by chip sliding (the secondary plastic deformation zone),

- and in the layer of the machined surface by sliding of the tool flank face (the tertiary plastic deformation zone).

Among other things, plastic deformation of the machined material in the cutting process causes:

- production of residual stresses in the surface layer of the machined surface,

- changing the texture of the material in the surface layer of the machined surface,

- chip formation,

- and mechanical and heat loading of the tool, which causes tool wear, affect the cutting forces, chatters etc.

The size and shape of the primary plastic deformation area depend mainly on:

- the physical properties of the material being machined (in particular its deformation and hardening properties),

- cutting speeds $\mathbf{v}_{\mathrm{c}}$,

- cutting environment,

- and tool geometry.

All of these are very important for good machining as a whole.

The tool geometry also includes a specific element, which is a chipbreaker (i.e., cutting parts with complicated face geometries). In case of sintered carbides, chipbreakers have been generally used, which is due to their production technology. However, using this essential element (chipbreaker) in the entire machining process, in case of PCD, has expanded with the development of machine technology, especially laser technology. Therefore, this area has not been widely studied. The works of Brecher [Brecher 2014], who tried to implement laser technology to the insert sharpening process, but without chipbreaker, can be mentioned. Dumitru [Dumitru 2005] discussed using laser in the production of cutting inserts. Applications of microstructuring of pores on the rake face acting as lubricant reservoirs and integral chipbreakers were two illustrative applications of the WC-Co inserts. [Rao 2018] investigated the benefits of micro-holes already in the PCD inserts when turning Ti-6Al-4V under the MQL cooling method. Three holes $(\varnothing 0,6 \times 1 \mathrm{~mm})$ were a product of EDM drilling. A modified insert showed a decrease in cutting temperature by $30-35 \%$ in contrast to a normal insert. Reduction in surface roughness was also observed and flank wear of the modified insert was also lower compared to a normal insert. Zeman [Zeman 2017] stated that the $0.1 \mathrm{~mm}$ diameter holes on the rake face of the WC-Co insert produced by laser showed an increase in tool life by $30 \%$ while machining titanium alloy. The modified macrogeometry of the tool in the form of an integral chipbreaker on the rake face helped to reduce cutting forces and increase tool life [Zeman 2017].

Nevertheless, a more implementation of laser technology and other new methods in the manufacturing of the PCD tool is needed in order to improve the machinability of difficult-to-cut titanium alloy. New possibilities of the chipbreakers of PCD tool, which have showed encouraging results [Zeman 2017] [Rao 2018], are important to be understood and further developed. This paper deals with the influence of the chipbreakers in terms of cutting forces and integrity of the machined surface (surface roughness and hardness) compared to a normal insert when dry-machined, which previous experiments did not consider. All these influencing factors are analysed also with respect to images of tool wear by scanning electron microscopy (SEM) and of the machined chip. 


\section{MATERIALS, DESIGN AND EXPERIMENTAL SET UP}

In the presented study, the Ti-6Al-4V titanium alloy (ASTM B265 or grade 5 titanium) was used as the workpiece material attractive for engineering. A microstructure of this alloy consists of a mixture of $\boldsymbol{\alpha}$ and $\boldsymbol{\beta}$ phases [Ezugwu 2003] [Kuljanic 1998] [Pittalà 2018] [Pramanik 2014]. It is widely used in vehicle, marine and offshore, aerospace, engines, gas turbine and biomedical industries due to its specific functional properties [Amin 2007] [Babik 2017] [Balazic 2007] [Corduan 2003] [Ezugwu 2003] [Ginta 2009] [Krishnaraj 2014] [Li 2013] [Nabhani 2001] [Oosthuizen 2011] [Pittalà 2018] [Pramanik 2014] [Rao 2018] [Safari 2014] [Shokrani 2012]. The highest strength-to-weight ratio among all other common metals up to $550^{\circ} \mathrm{C}$ [Haiying 2017] [Shokrani 2012], low density, superior corrosion and creep resistance, and high wear resistance are suitable for engineering parts [Amin 2007] [Corduan 2003] [Ezugwu 2003] [Ezugwu 2007] [Ginta 2009] [Krishnaraj 2014] [Li 2013] [Moussaoui 2015] [Nabhani 2001] [Oosthuizen 2011] [Pittalà 2018] [Pramanik 2014] [Rao 2018] [Safari 2014] [Shokrani 2012]. However, recommended using temperature for blades in a turbine is up to $350^{\circ} \mathrm{C}$ [Kuljanic 1998]. Medical industry, among the listed characteristics, uses the necessary feature, which is the capability of interacting with biological systems (biocompatibility), bioadhesion, osteointegration and chemical stability [Amin 2007] [Babik 2017] [Balazic 2007] [Krishnaraj 2014] [Nabhani 2001].

Titanium is categorized as difficult-to-machine material. Due to this, machining is associated with low productivity and high machining costs [Amin 2007] [Ezugwu 2003] [Ginta 2009] [Krishnaraj 2014] [Moussaoui 2015] [Oosthuizen 2011] [Pramanik 2014] [Rao 2018] [Shokrani 2012]. Relatively low thermal conductivity $\left(7 \mathrm{~W} \cdot \mathrm{m}^{-1} \cdot \mathrm{K}^{-1}\right)$ of these materials results in difficulties in heat dissipation, which is eight to ten times lower than that of steel [Shokrani 2012]. Approximately a quarter of created cutting heat is removed by chips, the rest by the tool [Balazic 2007]. High strength, hardness of the workpiece material and high strain hardening (work hardening due to their austenitic matrix) together with high cutting temperatures result in extensive tool wear and thus poor surface quality and reduction of tool life. Difficulties in chip formation and values of cutting forces are related with the above [Amin 2007] [Balazic 2007] [Corduan 2003] [Ginta 2009] [Krishnaraj 2014] [Moussaoui 2015] [Oosthuizen 2011] [Rao 2018] [Safari 2014] [Shokrani 2012].

In general, higher cutting speed means a decrease in tool life. But in some interval, a local maximum tool life may exist thank to phase transformation from $\boldsymbol{\alpha}$ to $\boldsymbol{\beta}$ phase [Corduan 2003] [Oosthuizen 2011]. However, Li [Li 2013] found no phase transformation was observed when machining Ti-6Al-4V by a PCD tool.

In addition to all complications, titanium is chemically reactive to all known tool materials, which results in diffusion and adhesion wear. BUE (built-up-edge), chips seizing onto the tool cutting surface, smearing or galling usually occur [B. da Silva 2013] [Corduan 2003] [Ezugwu 2003] [Krishnaraj 2014] [Oosthuizen 2011] [Shokrani 2012].

Serrated chips (saw-tooth chips) are formed during machining of titanium due to the combination of high yield stress ratio and low Young's modulus (104 GPa), which is reflected in small plastic deformations. This results in a deflection effect of a workpiece, cutting force fluctuations, machining instability and chatter that leads to the chipping of the cutting edge due to the variation of chip thickness [Amin 2007] [Balazic 2007] [Ezugwu 2003] [Oosthuizen 2011] [Pramanik 2014] [Shokrani 2012]. Chip segmentation could also occur due to formation of the adiabatic shear band, which is caused by the work hardening and the difficulty of dislocation motion [Pramanik 2014].

A $4.5 \mathrm{~mm}$ thick titanium sheet made of Ti-6Al-4V was used for the experiment. In Fig. 1, the typical structure of this alloy (mixture of $\boldsymbol{\alpha}$ and $\boldsymbol{\beta}$ phases) is shown in SEM image of the etched sample. The energy dispersive spectrometer (EDS) determined the chemical composition of the selected area of Fig. 1 (see Fig. 2).

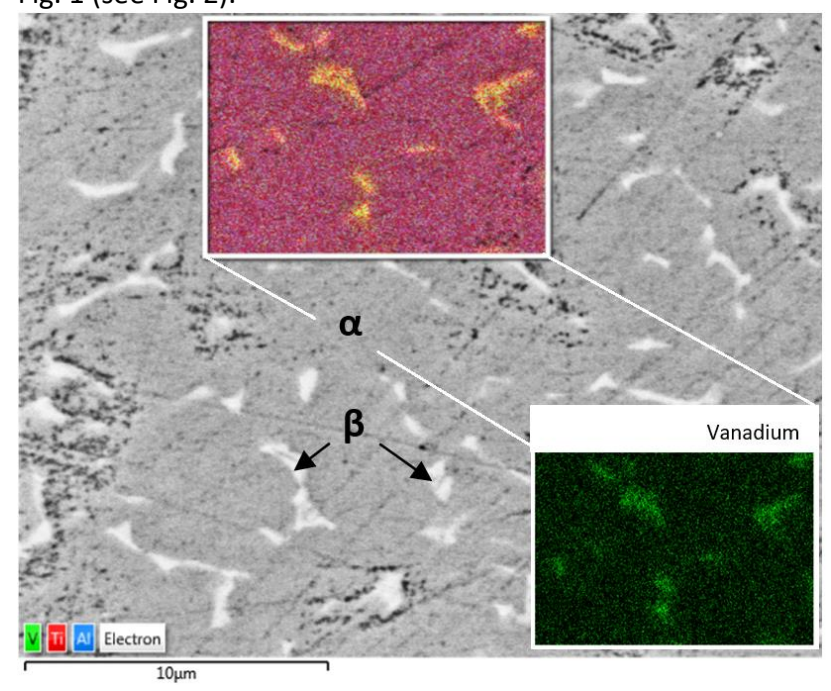

Figure 1. SEM Image of Ti6Al4V with Marked Area for EDS Analysis, including Vanadium Mapping.

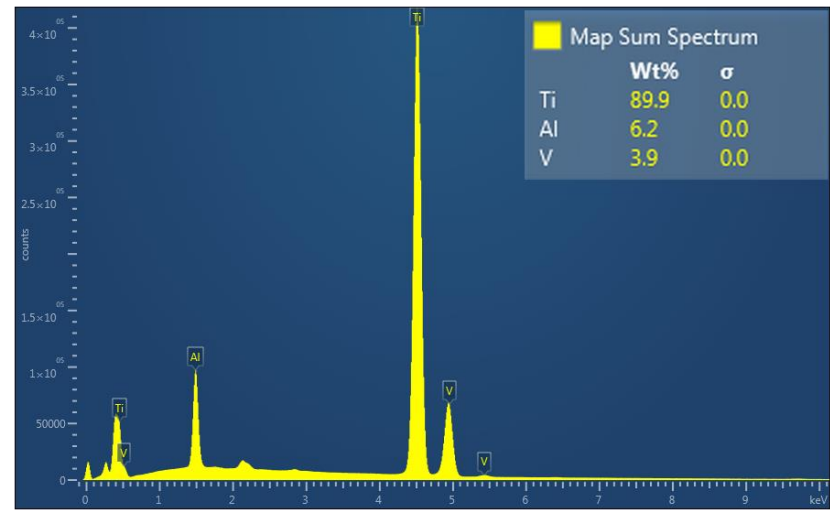

Figure 2. EDS Spectrum

Many researchers have studied the cutting performance of PCD tools when machining this advanced engineering material - titanium alloy. Higher tool life has been proven compared to other cutting materials and PCD has been preferred as the best candidate for machining of titanium alloys [Amin 2007] [Corduan 2003] [Ezugwu 2003] [Li 2013] [Nabhani 2001] [Oosthuizen 2011] [Shokrani 2012], [Su 2012]. Based on the results of study by Nabhani [Nabhani 2001]: PCD seems to be the most suitable cutting tool material for machining titanium alloys. PCD had the highest value of tool life and produced the best quality machined surface among CVD TiC/TiC-N/TiN triplecoated carbide and PCBN when the Ti alloy was dry machined [Nabhani 2001].

Optimal cutting speed was defined by Amin [Amin 2007] when milling Ti-6Al-4V in the range of $120-160 \mathrm{~m} \cdot \mathrm{min}^{-1}$ for PCD tool. While using WC-CO the speed was two to three times lower. $120 \mathrm{~m} \cdot \mathrm{min}^{-1}$ was the examined lowest $\mathbf{v}_{\mathbf{c}}$ in case of PCD. However, increasing speed meant an increase in average surface roughness $\mathbf{R a}$, which was still lower using PCD inserts compared to that using uncoated WC-Co. That was due to lower wear rate and smaller chatter in the case of PCD.

PCD has four times higher thermal conductivity than tungsten carbide [Oosthuizen 2011] and higher hot hardness 
(the softening temperature) than other available cutting materials [Ezugwu 2003] [Oosthuizen 2011]. This helps to dissipate the generated heat while machining Ti alloys.

Titanium is a strong carbide-forming element [B. da Silva 2013] [Kuljanic 1998]. However, the interfacial protective cutting tool layer of a titanium carbide (TiC) could be formed on the rake face of PCD [Corduan 2003] [Ezugwu 2003] [Kuljanic 1998] [Nabhani 2001]. In addition, the TiC is more stable than diamond [Corduan 2003].

The choice of cutting conditions is a key factor in the entire cutting process. It is envisaged that up to $20 \%$ of production cost could be saved when using the correct machining conditions and tooling [Ezugwu 2005].

Prototype tools were designed with regard to their production, sharpening and application in experimental machining - right-hand end mills with brazed insert. Due to the long tool life of PCD, the mills had one brazed insert - Fig. 3.

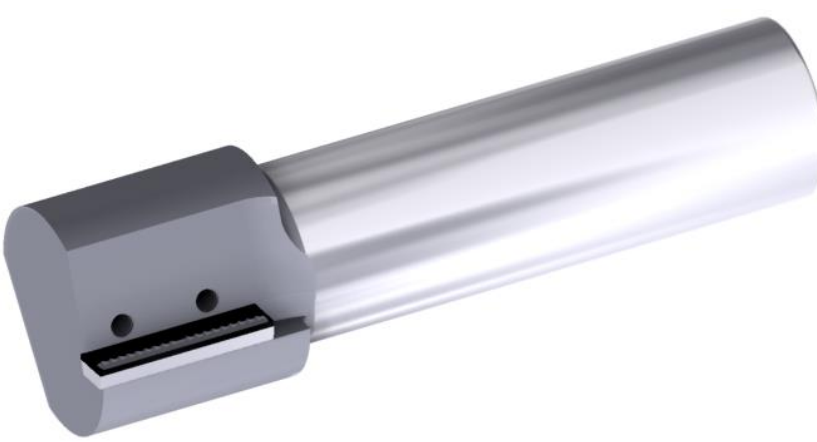

Figure 3. 3D Model of Prototype Tool.

The manufacturer recommended grade of PCD (ElementSix)

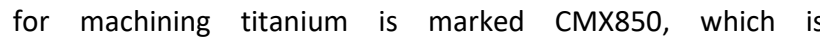
characterized by an average grain size of $1 \mu \mathrm{m}$ [Elementsix 2016]. The thickness of a circular blank was $2 \mathrm{~mm}$ with a PCD layer of $0.5 \mathrm{~mm}$. The CMX850 grade was also used by Oosthuizen [Oosthuizen 2011].

Fine-grained microstructure of this PCD is shown by scanning electron microscopy in Fig. 4. This surface eroded with electric discharge machining - grinding (EDM-G) showed typical surface of moon landscape - regularly torn diamond grains. In Fig. 5 and 6 a difference of the machined surface using the abovementioned electrical technology and laser could be seen, which works on so-called cold ablation principle.

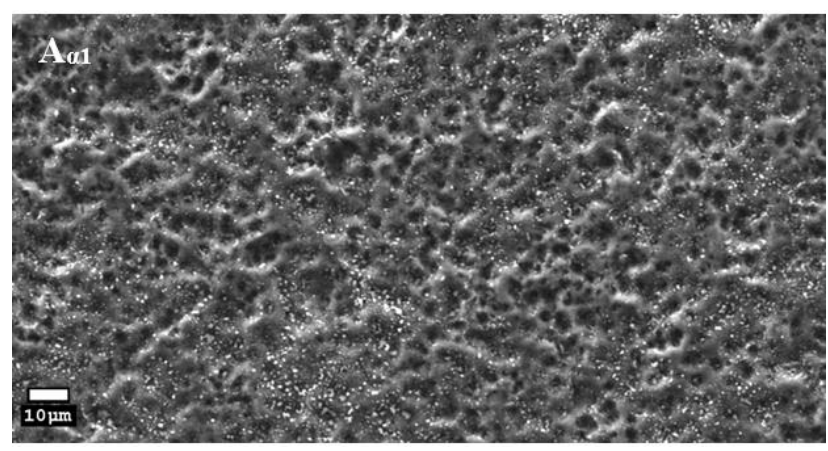

Figure 4. Fine-grained microstructure of PCD - CMX850.

A total of four prototype tools were produced. All of these had the same body geometry and thus also seat position, which meant that cutting angles were for each endmills also same. However, three modifications of the polycrystalline diamond rake face were proposed to make the cutting process itself more effective and to increase the tool life. These modifications, including sharpening, were carried out by laser technology (specifically on machine EWAG Laser Line Ultra). For comparison, one insert was with a standard unmodified face (sample labelled 1), which contained a flat layer of polished PCD sintered to the base of the sintered carbides. The modified insert $\mathbf{4}$ had the same geometry as $\mathbf{1}$, but holes with diameters and depths of tenths of a millimetre were created on the rake face of the insert based on the results by [Zeman 2017] and [Rao 2018], but without using the cutting fluid. The edges of the holes on the plate were rounded for easier chip flowing. The bevel angle of the holes had to have a $20^{\circ}$ technological value. Another two end mills, labelled as $\mathbf{2}$ and $\mathbf{3}$, already had significant integral chipbreakers. In both cases, the design was aimed at reducing the interface between the tool and the outgoing chip, as well as achieving a more positive geometry while maintaining the rigidity of the tool. There were drops in case of 2. In the third case, part of the chibreaker surfaces was reduced into a valley form. All tools were manufactured under the same process conditions. Therefore, a comparable quality of sharpening can be expected. For clarity, Tab. 1 of the produced tools and the geometry of the chipbreakers in Fig. 712 are shown.

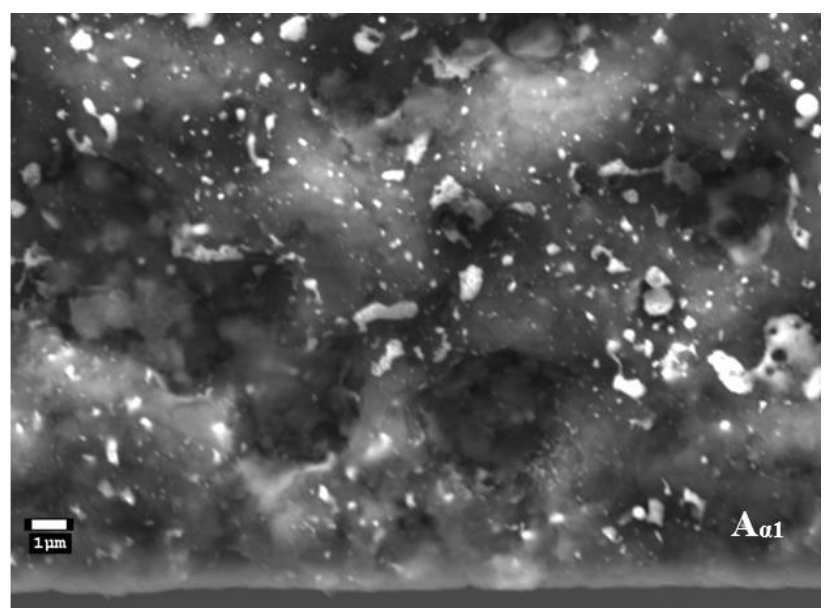

Figure 5. The Surface of The Primary Main Flank Face Sharpened by EDM-G Technology.

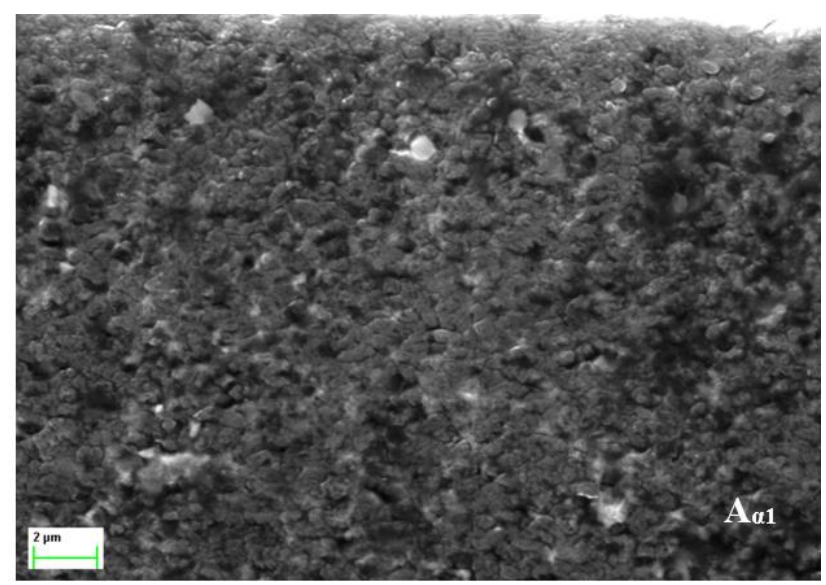

Figure 6. The Surface of The Primary Main Flank Face Sharpened by Laser Technology.

\begin{tabular}{|l|l|l|}
\hline Endmill & Chipbreaker & Labeling \\
\hline $\mathbf{1}$ & - (without) & 268518005.1 \\
\hline $\mathbf{2}$ & drops & 268518005.2 \\
\hline $\mathbf{3}$ & valleys & 268518005.3 \\
\hline $\mathbf{4}$ & holes & 268518005.4 \\
\hline
\end{tabular}

Table 1. Types of endmill. 
To implement the dry machining, it is necessary to the choose the right cutting tool materials (progressive direction is using of new material [Ginta 2009]), last but not least cutting parameters and cutting tool geometry [Shokrani 2012], which was another important step in the experiment. Ji [Ji 2015] investigated the effects between tool geometry and tool performance. He found out that using a smaller radial rake angle meant increasing the tool life when milling the TC11 titanium alloy by a PCD tool. Specifically, this angle was tested at three levels $\left(1^{\circ}, 6^{\circ}\right.$ and $\left.11^{\circ}\right)$. For this reason, the tool side rake $\left(\boldsymbol{\nu}_{\mathrm{f}}\right)$ excluding chipbreaker had the value of $1^{\circ}$. In the case of the two integral chipbreakers, major cutting edge had a chipbreaker land width and basic rake angle within chipbreaker had value of $10^{\circ}$ - light brown lines in Fig. 7-10. Thus, together with tool body and chipbreaker geometry, the positive $\gamma_{f}$ was up to $11^{\circ}$, which was also the highest level tested by Ji [Ji 2015]. Tool side clearances $\left(\boldsymbol{\alpha}_{\mathrm{f} 1}\right.$ and $\left.\boldsymbol{\alpha}_{\mathrm{f} 2}\right)$ were $12^{\circ} / 18^{\circ}$ and the tool cutting edge angle $\left(\mathbf{K}_{\mathbf{r}}\right)$ was $90^{\circ}$ for all tools.

The tools were designed with respect to a degree of out-ofbalance. This was checked also after production/sharpening on a Haimer tool dynamic balancing machine.

Arithmetical mean height of the scale limited surface (Sa) of

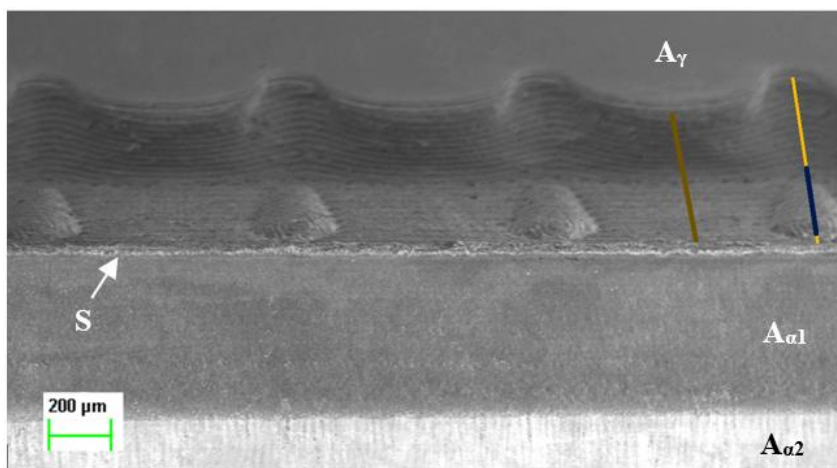

Figure 7. Chipbreaker 2.

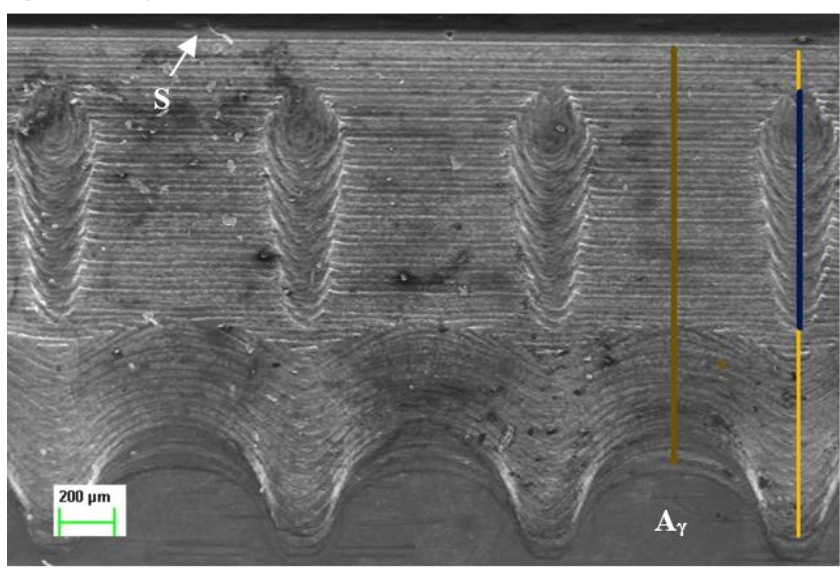

Figure 8. Chipbreaker 2 - rake face view.

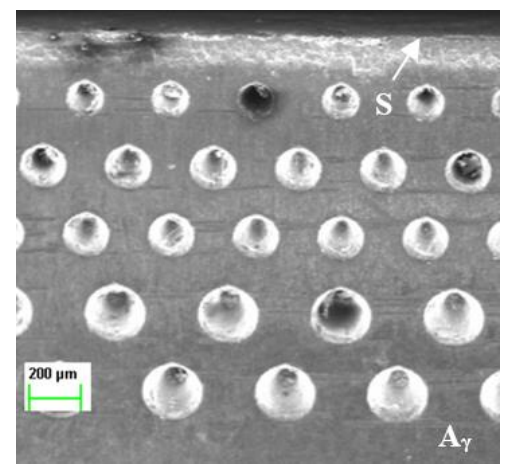

Figure 11. Chipbreaker 4 chipbreaker surface machined by laser was $0.7 \mu \mathrm{m}(\mathrm{s}=0.9 \mu \mathrm{m})$, while the not machined flat layer of polished PCD by the manufacturer reached the value of Sa $0.1 \mu \mathrm{m}(\mathrm{s}=0.1 \mu \mathrm{m})$. This inspection of roughness was performed on the Alicona InfiniteFocus optical microscope. Machine times to produce individual chipbreakers (without sharpening) were comparable (about 20 minutes). It was the first production. Subsequent production could further improve the machining strategy and thus reduce these machine times.

The schematic experiment set up can be seen in Fig. 13. Since the aim of the experiment was to verify the function of the chipbreakers, the type of milling was side milling and thus the results were not affected by the transition to the minor cutting edge that did not take part in the milling. For this reason, the tool cutting edge inclination $\left(\boldsymbol{\lambda}_{s}\right)$ was $0^{\circ}$.

The cutting conditions used for the experiment are shown in Tab. 2. In the machining of difficult-to-cut materials where a large amount of heat is generated, it is generally advisable to use a smaller value of $a_{e}$ and a greater value of $a_{p}$ in order to dissipate the generated heat by the larger tool area.

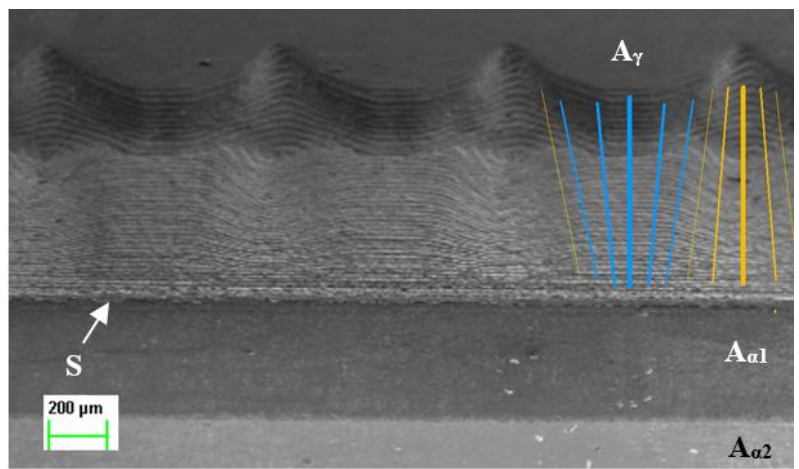

Figure 9. Chipbreaker 3

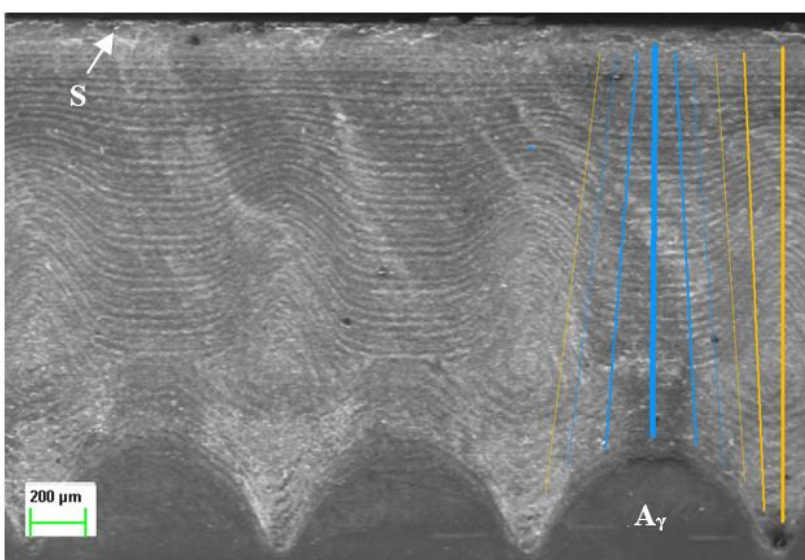

Figure 10. Chipbreaker 3 - rake face view

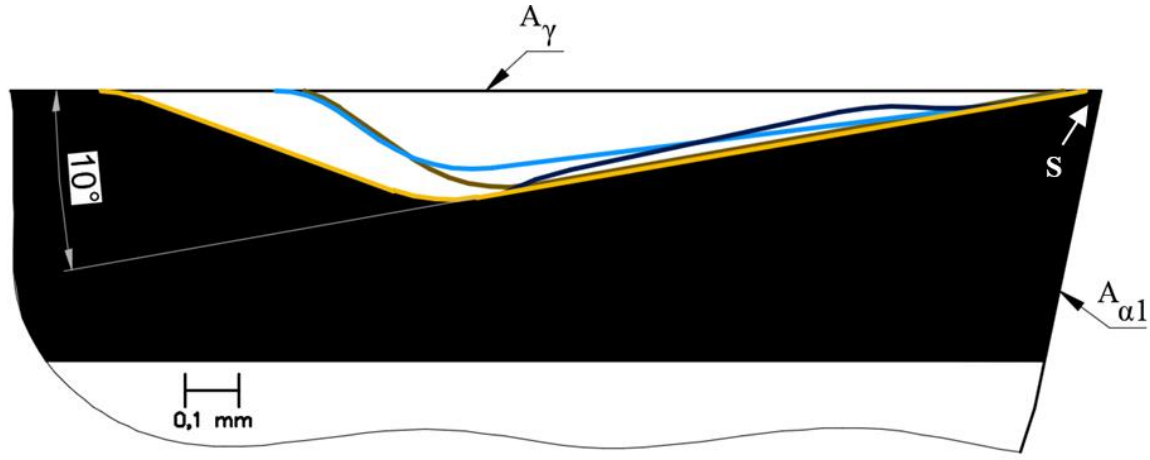

Figure 12. Scheme of chipbreaker 2 and 3. 

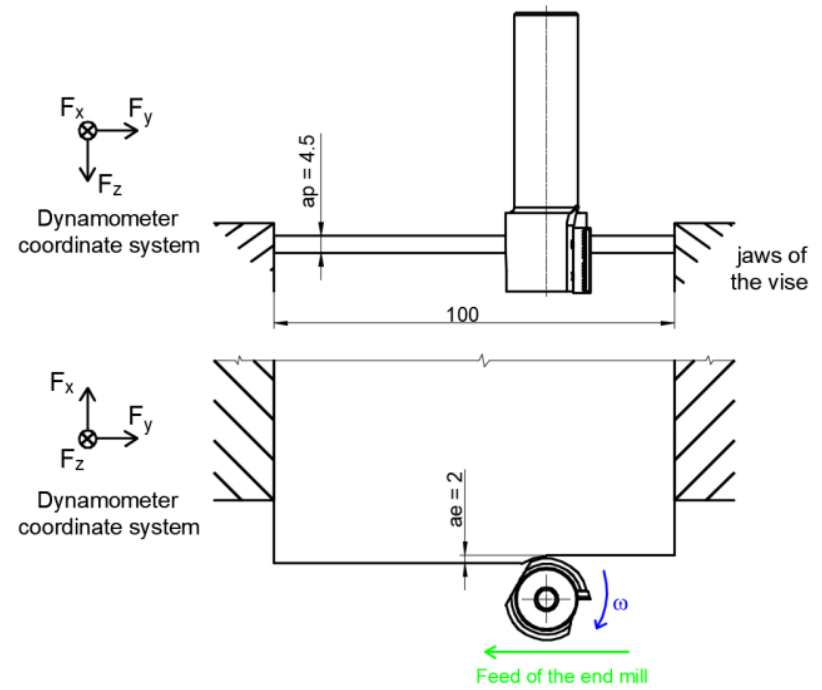

Figure 13. Milling Scheme for Force Recording.

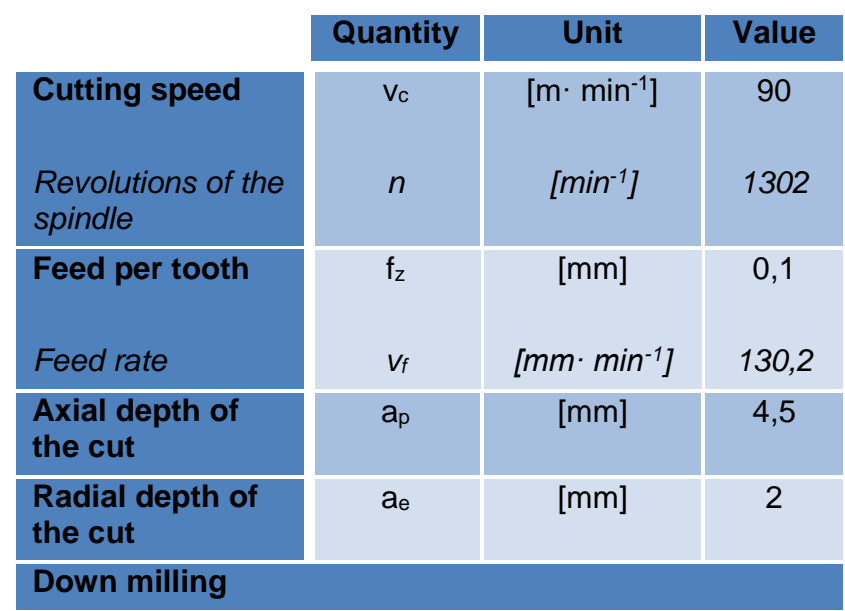

Table 2. Cutting Conditions.

The feed per tooth was chosen with respect to the value of $a_{e}$ and the value of chipbreaker land width, which had a size of $0.03 \mathrm{~mm}$ according to the 3D model. The aim was to achieve a chip thickness greater than the chipbreaker land width. For this reason, a feed of $0.1 \mathrm{~mm}$ was chosen, at which the nominal maximum chip thickness was $0.057 \mathrm{~mm}$. In case of machining materials with the high strain hardening, it is also advisable to get below this hardening layer by cutting edge and machine as few passes as possible.

In addition to these parameters, it was necessary to appropriately select the cutting speed value. It influences the tool life most and is related to the generated heat. Researchers [Amin 2007] [B. da Silva 2013] [Corduan 2003] [Ezugwu 2005] [Ezugwu 2007] [Ji 2015] [Kuljanic 1998] [Nabhani 2001] [Rao 2018] used cutting speed for PCD approximately in the range of $75 \mathrm{~m} \cdot \mathrm{min}^{-1}$ to $250 \mathrm{~m} \cdot \mathrm{min}^{-1}$ when machining $\mathrm{Ti}$ alloys. The specific value depended on technological operation, cooling, required tool life and other cutting parameters (e.g. $\mathbf{f}_{\mathbf{z}}$, etc.). For example, Oosthuizen [Oosthuizen 2011] tested cutting conditions when milling grade 5 titanium alloy by PCD (grade CMX850). Higher cutting speed meant reduction in tool life. Li [Li 2013] investigated the effects between cutting speed and material removal rate when turning Ti-6Al-4V by a PCD insert. The range of $\mathbf{v}_{\mathbf{c}}$ was extremely high, i.e. 250 to $2000 \mathrm{~m} \cdot \mathrm{min}^{-1}$. For $250 \mathrm{~m} \cdot \mathrm{min}^{-1}$ maximum flank wear was more than $0.2 \mathrm{~mm}$ after $160 \mathrm{~s}$ of cutting time (material removal volume was 437.5 $\mathrm{mm}^{3}$ ). Catastrophic tool failure was observed from $375 \mathrm{~m} \cdot \mathrm{min}^{-1}$ after the same value of material removal volume $\left(437.5 \mathrm{~mm}^{3}\right)$.
The most widely used and recommended cutting speed was around $100 \mathrm{~m} \cdot \mathrm{min}^{-1}$. To avoid short tool life, catastrophic breakage of the tool and with regard to feed per tooth and dry machining, $90 \mathrm{~m} \cdot \mathrm{min}^{-1}$ was selected. This value is also in the middle of the manufacturer's recommended value interval [Elementsix 2016].

All measurements were carried out on a CNC vertical milling centre. The cutting forces were measured with a piezoelectric Kistler dynamometer (type 9257B) connected to a charge amplifier. The realistic set up for force recording can be seen in Fig. 11.

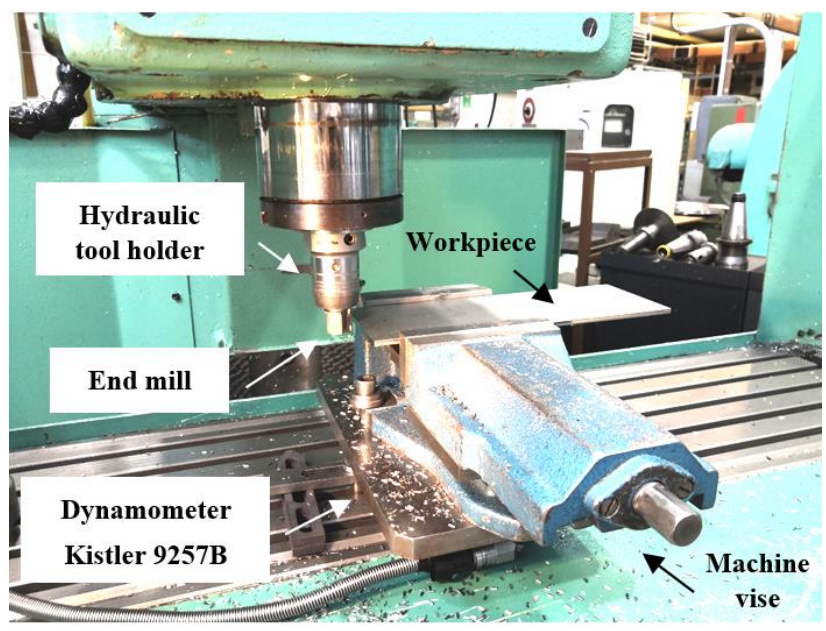

Figure 14. Workpiece and Dynamometer Set up.

Scanning electron microscope was used for identifying the wear mechanism(s) of the inserts and capturing chips removed by individual tools. Machined surface integrity was analysed by the contact roughness method on the Form Talysurf Intra 50 (manufactured by Taylor Hobson) with a radius of the scanning tip $2 \mu \mathrm{m}$ and by a hardness tester machine.

\section{CUTTING ENVIROMENT}

As mentioned above, generated heat during machining means difficulties in heat dissipation through the workpiece and chips of titanium alloys. The interface temperatures are extremely high and concentrated near the cutting edge [Ezugwu 2003]. Therefore, heat should be dissipated through the cooling media or cutting tool [Ezugwu 2003] [Shokrani 2012]. Using the cutting fluids is one of the most common technique for improving machinability and decreasing tool wear, such as adhesion or diffusion [Shokrani 2012]. Ezugwu [Ezugwu 2007] explains the cutting speed can be increased by up to $50 \%$ with effective chip breakage by high-pressure cooling. This cooling is found to be the most effective cooling method in machining $\mathrm{Ti}$ alloys [Pramanik 2014]. Ezugwu [Ezugwu 2005] also mentions the benefits of high-pressure cooling when machining Ti-6Al-4V with PCD.

As mentioned in the introduction, the cutting environment also affects the size and shape of the primary plastic deformation area. A pre-experiment and a self-contained chapter are included in this part of paper, in which dry and wet machining was compared with our specific cutting conditions with the end mill 1, which was sharpened by EDM-G in this case. The cutting speed was increased to $150 \mathrm{~m} \cdot \mathrm{min}^{-1}$, as the cutting tool wear rate is generally smaller during wet machining [Shokrani 2012] and since machining was carried out with the toughest tool. Machining of sheet metal thickness of $2.5 \mathrm{~mm}$ was performed.

This pre-experiment was conducted on the Tajmac-ZPS MCV 1210 5-axis CNC milling machine with the SINUMERIK control 
unit, which enable the supplying of cutting fluid through the centre of the tool and the outlet was directly to the cutting edge. B. da Silva [B. da Silva 2013] reported that the highest tool life had been achieved at the highest tested pressure $(20.3$ $\mathrm{MPa}$ ) while using the same workpiece and tool material (Ti-6Al$4 \mathrm{~V}$ respectively $\mathrm{PCD}$ ). Due to this, coolant pressure of $25 \mathrm{MPa}$ was applied. High pressure cooling system was directed either to the chip-tool interface or overhead [B. da Silva 2013] - Fig. 15.

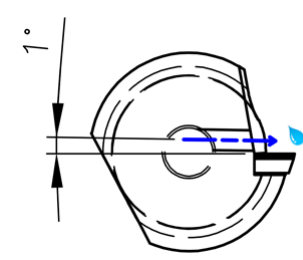

Figure 15. High pressure cutting fluid supply.

The presence of chlorine additives in cutting fluids is not recommended in the machining of titanium alloys [Balazic 2007] [Shokrani 2012]. This constituent is also considered as hazardous substance for workers' health and environment [Shokrani 2012]. Chlorine-free water miscible metalworking fluid (CIMCOOL CIMSTAR 597) at $10 \%$ volumetric concentration was applied [Piska 2016].

The forces resultant in the radial plane $\mathbf{x y}-\mathbf{F}_{\mathbf{x y}}$ - were evaluated - see Fig. 16 . They were calculated from a relation (1).

$$
F_{x y}=\sqrt{F_{x}^{2}+F_{y}^{2}}
$$

The obtained results showed that these cutting conditions were not suitable for cutting forces - Fig. 16. This can be attributed to the combined effect of tool geometry, cutting conditions and high-pressure cooling used during the milling process. Chips were probably formed back to the tool edge and pulled toward the machined surface, which increased the cutting forces. This forming can be confirmed by optical microscope images where the workpiece material adheres to the rake face of the insert see Fig. 17 and 18.

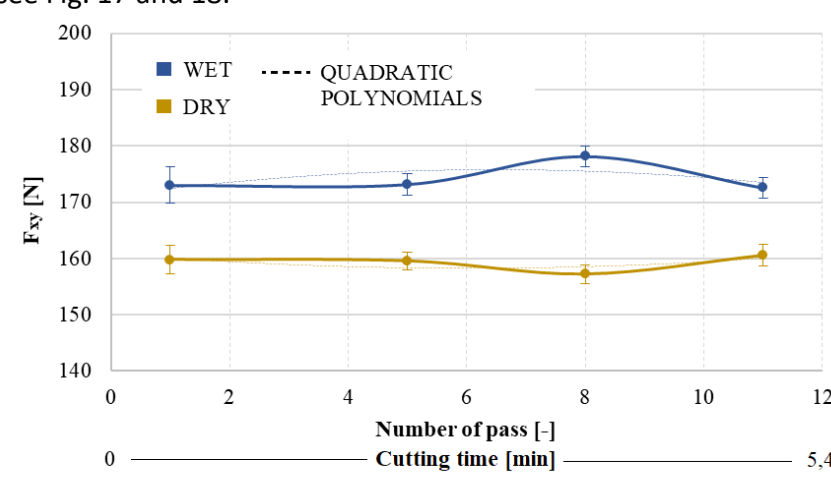

Figure 16. Graph of Forces in The Radial Plane for Cutting Environment.

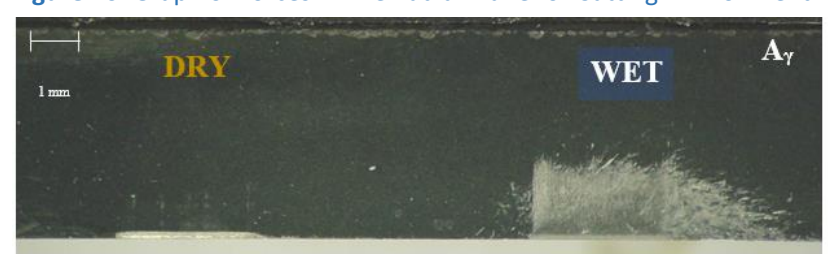

Figure 17. Rake Face of the Insert.

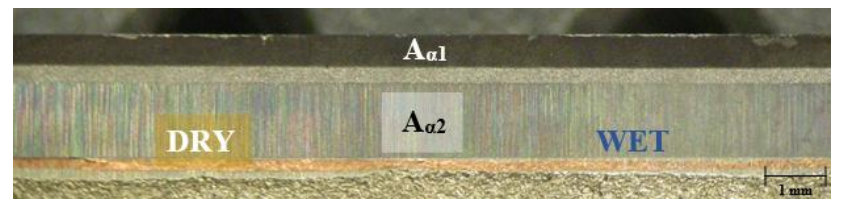

With this experiment, it was not possible to unambiguously determine the trend of the development of cutting forces and thus the tool life. Results by B. da Silva [B. da Silva 2013] had also a fluctuation of the cutting forces. Conventional cooling achieved lower forces than for high pressure cooling in an interval of $\mathbf{v}_{\mathbf{c}}$, which was also the trend of the stated results. However, tool life was always higher for high pressure cooling [B. da Silva 2013]. On the other hand, [Shokrani 2012] stated higher cutting forces are not generally suitable with respect to tool/machine loading, could reduce the tool life, are not suitable for thin-walled workpieces and increase vibration and chatter (thus surface roughness).

However, many emulsions have a major impact on the environment and the operator's health. Together with developing governmental regulations, it has resulted in increasing machining costs for different components [Ezugwu 2003] [Safari 2014] [Shokrani 2012]. It is estimated that the costs associated with cutting fluids while machining difficult-tomachine materials can reach 20-30 \% of the total manufacturing costs. For comparison, the cost for tooling is usually about 2-4\% [Shokrani 2012]. In case of discontinous processes, e.g. milling, thermal damage of the cutting edge can occur when using a cutting fluid, such as thermal crack [Kuljanic 1998].

Cryogenic cooling can be a solution to reducing the use of common cooling fluid [Ezugwu 2003] [Ezugwu 2005] [Pittalà 2018] [Shokrani 2012]. These gaseous coolants are relatively cleaner and more environmentally friendly than conventional cutting fluids. However, they require additional equipment [Ezugwu 2005] [Pittalà 2018] [Shokrani 2012]. By using liquid nitrogen (LN2) when turning Ti-6Al-4V, tool life could be improved by up to 3.3 times [Shokrani 2012]. Cryogenic cooling is found to be more efficient than high pressure cooling [Pramanik 2014].

In contrast, pre-heating (ion-beam, plasma heating and induction heating) of the workpiece can also significantly increase the tool life, as the workpiece becomes more machinable and reaches an optimal cutting temperature - this is another technique to eliminate the use of conventional cutting fluids [Shokrani 2012]. Ginta [Ginta 2009] focused on the preheating, which helps in increasing tool life when end milling Ti-6Al-4V by WC-Co. Preheating at $650^{\circ} \mathrm{C}$ increases the tool life by 3.25 times and reduces the magnitude of cutting force. But BUE was found in all cases. On the other hand, increases in the cutting temperature are not beneficiary due to the high strength of titanium even at very high temperatures. Cutting tools can suffer from heat softening [Shokrani 2012].

For the machining of difficult-to-cut materials, the combination of heating of the workpiece and cryogenic cooling of the tool is sometimes used, which is called hybrid machining [Pramanik 2014].

In addition to the mentioned techniques, another technique to eliminate the use of conventional cutting fluids is dry machining, which is aimed at in this paper.

\section{RESULTS AND DISCUSSION}

During and after dry machining, the following cuttingprocess related issues were measured.

\subsection{Cutting forces}

Experimental machining took 18 minutes. Trends of the $\mathbf{F}_{\mathbf{x y}}$ cutting force resultants during this time period were plotted in Fig. 19. As it mentioned above, the milling cutters $\mathbf{1}$ and $\mathbf{4}$ were

Figure 18. Flank Face of the Insert. 
geometrically the same, except that $\mathbf{4}$ had created holes on the rake face of the insert. This macro modification helped to

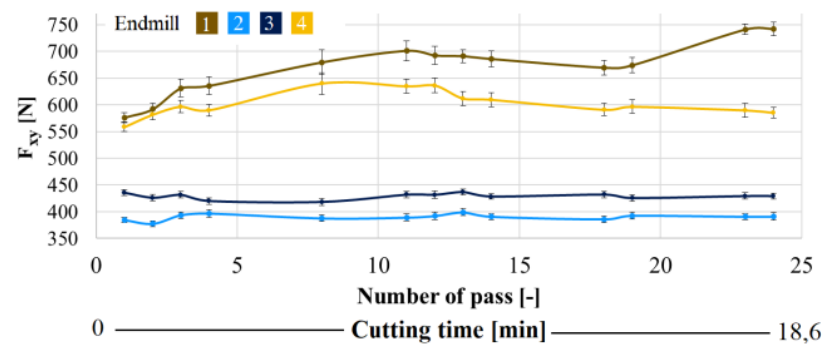

Figure 19. Graph of Forces in The Radial Plane.

reduce the cutting forces. The trend in the development of cutting forces had an ever-increasing character for the end mill 1. In case of end mill 4, the increase in the force load stopped after 10 minutes of machining. Tools $\mathbf{2}$ and $\mathbf{3}$ had an integral chipbreaker, making their geometry more positive, which was also confirmed lower force loading. However, it was not possible to determine a more suitable integral chipbreaker, because of the slightly different geometry described above (Fig. 7-12), and, in particular, the size of the chipbreaker land width, which ensured the cutting-edge stiffness. According to the SEM images, the size of the chipbreaker land width was $60 \mu \mathrm{m}$ for tool 3 (Fig. 20), and no land width was detected for tool 2 (Fig. 21), which greatly increased the positivity of the tool. Thus, precision of the production of chipbreakers by laser has a significant impact on the resulting force loading during machining. However, the cutting forces of these two mills remained constant throughout the whole experiment. An increase in cutting force indicated an increase in tool wear, thereby more positive geometry showed better results. The stated results were contrary to the study by Ji [Ji 2015], where the machined workpiece was TC11 titanium alloy.

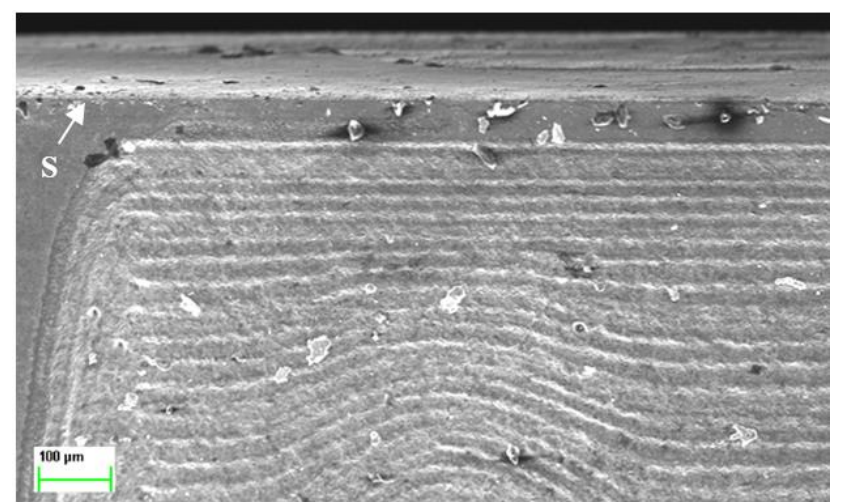

Figure 20. Land Width of The ChipBreaker 3.

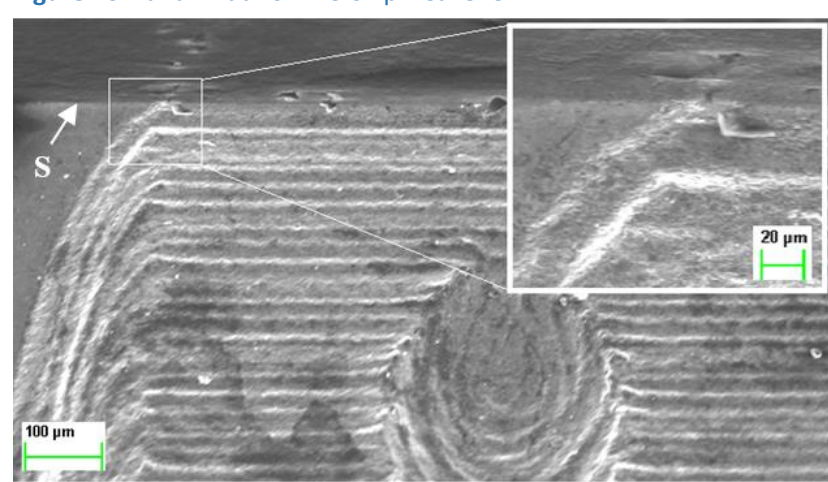

Figure 21. No Land Width of The ChipBreaker 2.

\subsection{Surface integrity}

Surface integrity is a key property in the functional performance of machined parts and assembled engineering components. The influence of the chipbreakers on surface roughness in feed direction was observed, which is one method of its evaluation.

The lowest Ra value was recorded for the end mill 1, which had the least positive geometry. This could be due to the smoothing of the machined surface by formed chips during down milling. Chips were taken away poorly and formed back to the tool edge and pulled toward the machined surface compared to more positive-geometry end mills. However, another explanation could be an increase in a rounded cutting edge radius due to the adhering of workpiece material. In summary, more positive geometry caused increasing the Ra value, which corresponds to Ji [Ji 2015]. Respectively higher cutting force means lower Ra. However, due to increased wear, the Sa value of the machined surface can be different than Ra. Also, textured surfaces of implants integrate better with bone via osseointegration process compared to smooth surfaces [Babik 2017].

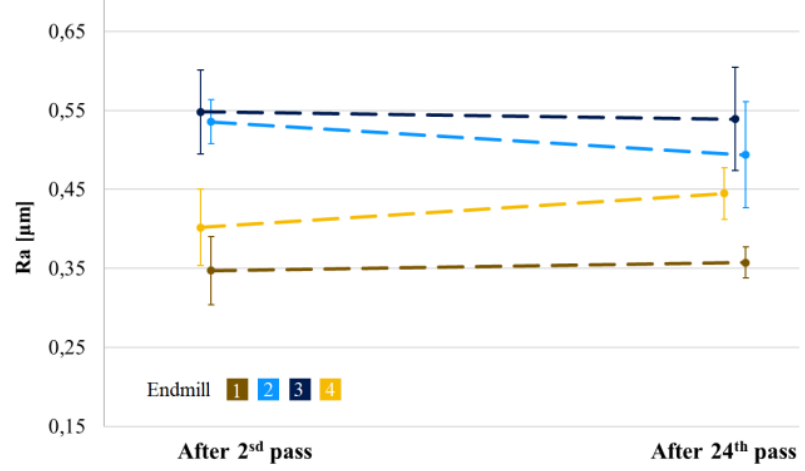

Figure 22. Ra values of machined surface.

Hardness is another parameter characterizing the integrity of the machined surface. In all four cases it was found out that: higher cutting force caused increasing the HV of the machined surface and thus the surface is more affected. Partially, it confirmed the theory mentioned in section Ra when the machined surface was more formed by the chip or deformation process during chip formation.

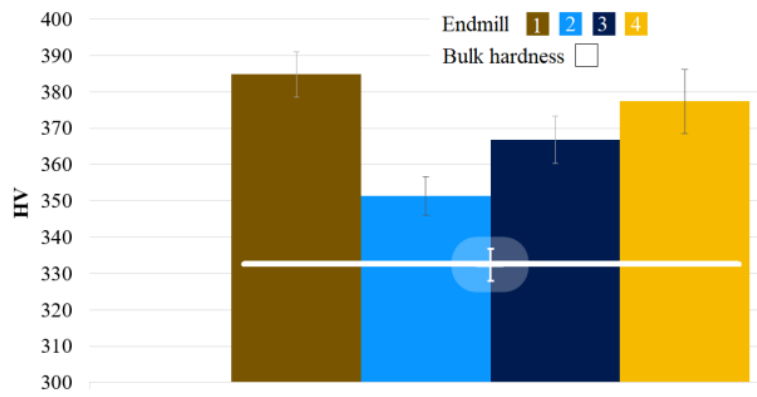

Figure 23. Vickers Hardness with 100 g loading.

\subsection{Chip formation}

Although chips are by-products of machining, they can tell about the cutting process itself. There was no significant difference between the individual chips, except the chip machined by tool 2, i.e. chipbreakers with drops. A characteristic sign of grooves (scratches) made by drop elements in the chipbreaker could be seen in Fig. 24. However, they are not always fully demonstrable, this could reduce the interface between the rake face and the outgoing chip. 


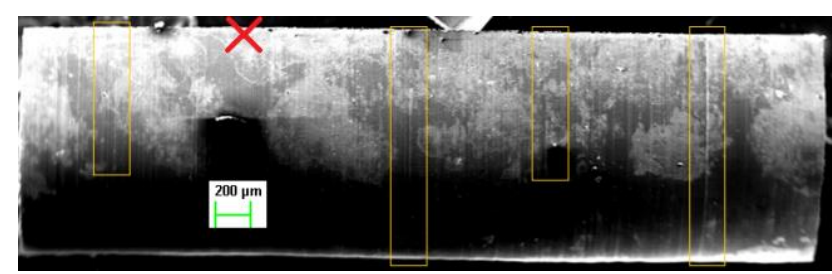

Figure 24. Chip created by end mill 2.

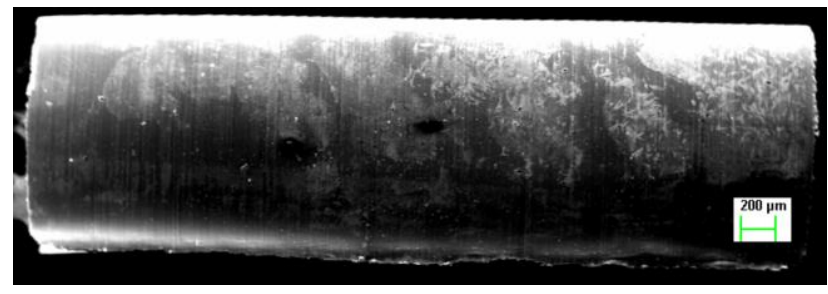

Figure 25. Chip created by end mill 4 .

\subsection{Tool wear}

Adhered material was detected on all tools and was formed up to BUE - see Fig. 26-29. Oosthuizen [Oosthuizen 2011] confirmed that the BUE is the material of the workpiece. $\beta$ phase with BCC lattice has strong tendency to adhere - [Kuljanic 1998].

There was a significant formation of adhered material for tool 1 and $\mathbf{4}$. In the following measurement of end mill 1, the thick layer of adhered material was found conversely on the left - a light ellipse Fig 26. In case of tool 4, the adhered layer was not found at all. As a result, this adhered layer in the form of a BUE was continuously forming and disappearing. This also generated more smeared material particles on the surfaces. In case of mills with integral chipbreakers, the adhered layer was significantly lower; thereby could be supposed that machined surface contained less smeared material particles or debris (Fig. 27-28).

Fig. 30 shows the adhered material in the form of deposits on the rake face of insert 1 . These deposits occurred on both sides of the leaving chip. In the following measurement (Fig. 31), they were not found at all, i.e. they were probably torn off after reaching a certain limit. The exact same situation occurred for end mill 4. Deposit was detected after the 1st measurement, then it did not occur, and it was detected again at the end of the measurement - Fig. 32-34. In this case, changing the position of the workpiece relative to the cutting edge would be advisable to avoid the deposit - there would not be a strong withholding of outgoing chips. It is also suitable to avoid notch wear. Another solution may be to make $a_{p}$ higher than the active width of the chipbreaker, but it would greatly reduce the versatility of the tool. In the active part of the chipbreaker, the holes were not sealed with the workpiece material - the holes were still fully functional (also in Fig. 36)

Fig. 35 and 36 confirmed the fact that the adhered layer is torn off after reaching a certain limit.

Fig. 38 and 39 showed the outer surface of the flank face where the active part of cutting edge ended. A dark area detected by a secondary electron detector (SED) occurred for all the tools. This was a carbon area, which could be a partial graphitization [Corduan 2003] or an abrasive region caused by a hardened layer with possible burrs from a previous passage, as this layer is harder than the bulk material.

Integral chipbreakers showed the intended reduction in the contact area between the chip and the tool face, since the workpiece material adhered to some of raised surfaces (Fig. 39 and 40). However, the machined material was quickly rolled into the form of chips, so it would be advisable to move these raised surfaces closer to the cutting edge to increase this effect.

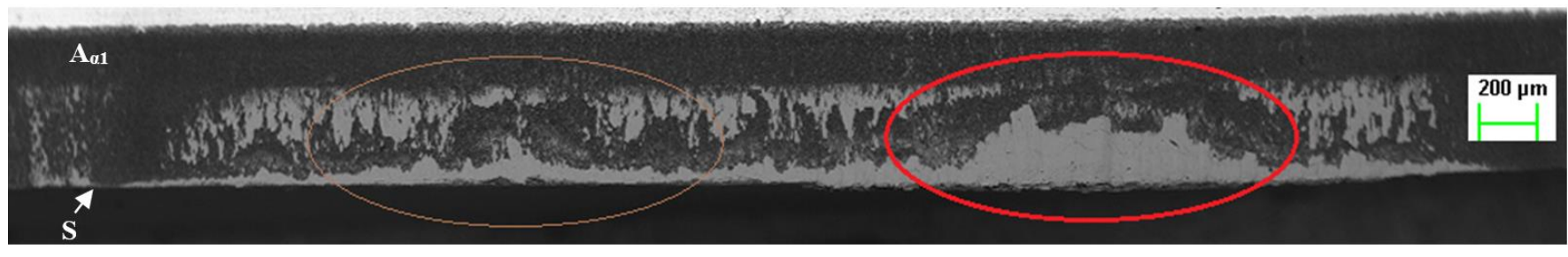

Figure 26. Flank Face of End Mill 1

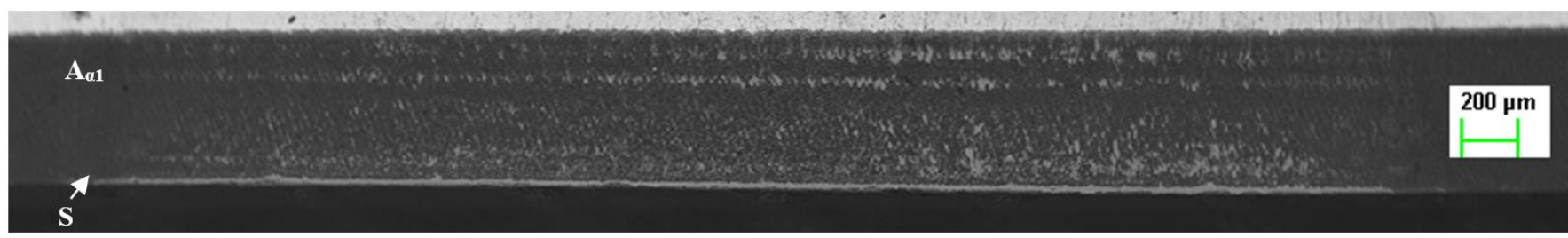

Figure 27. Flank Face of End Mill 2.

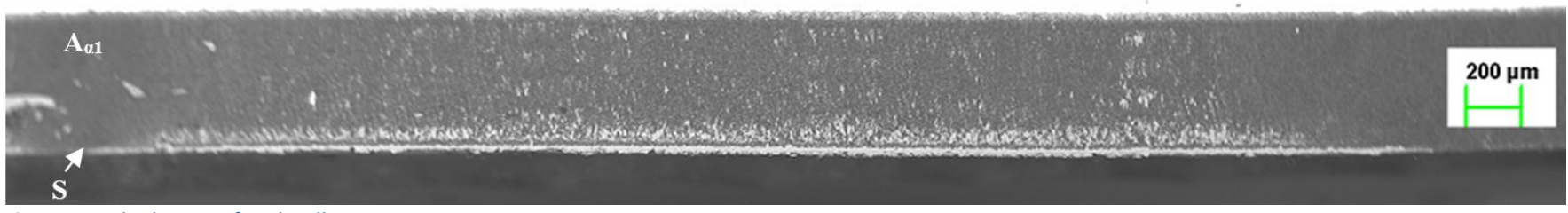

Figure 28. Flank Face of End Mill 3.

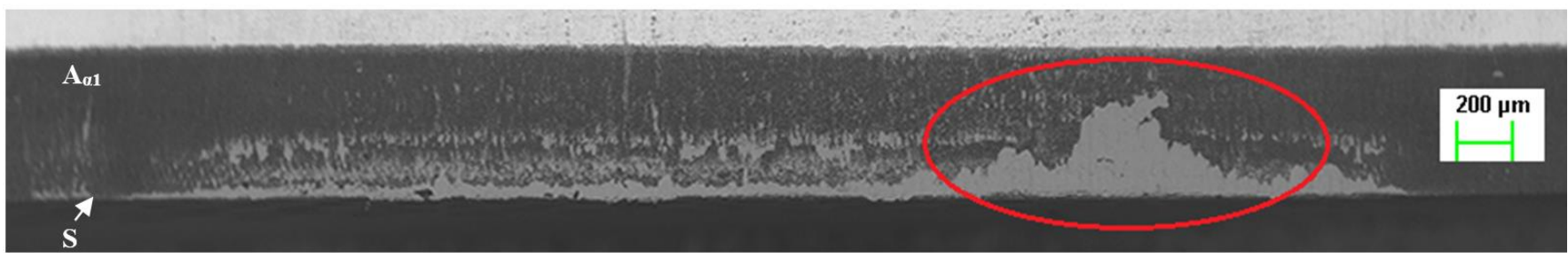

Figure 29. Flank Face of End Mill 4. 


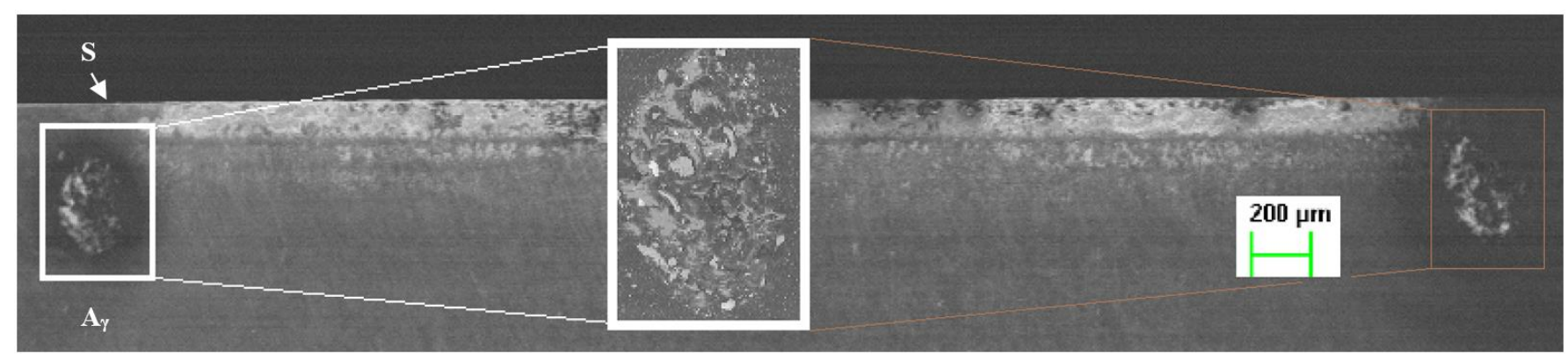

Figure 30. Rake Face of End Mill 1 after $1^{\text {st }}$ measurement.

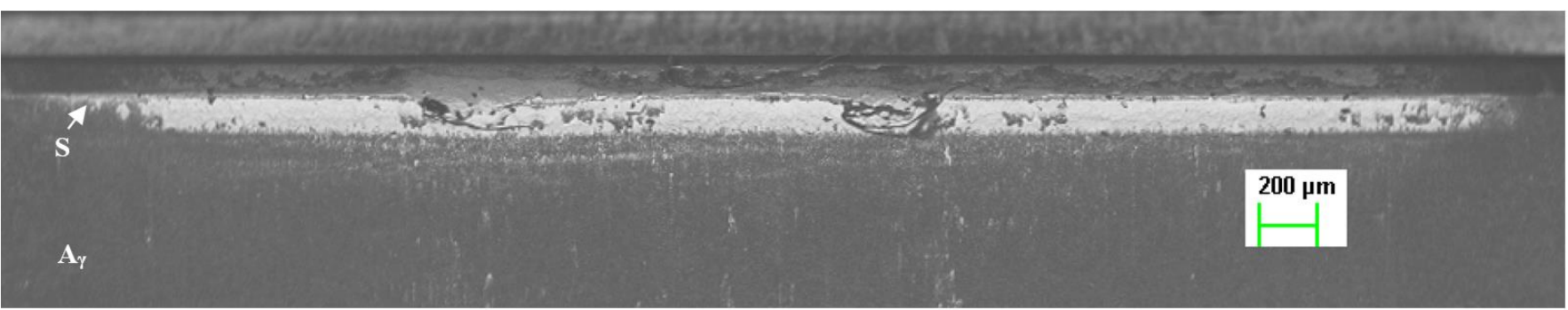

Figure 31. Rake Face of End Mill 1 after $3^{\text {rd }}$ measurement.

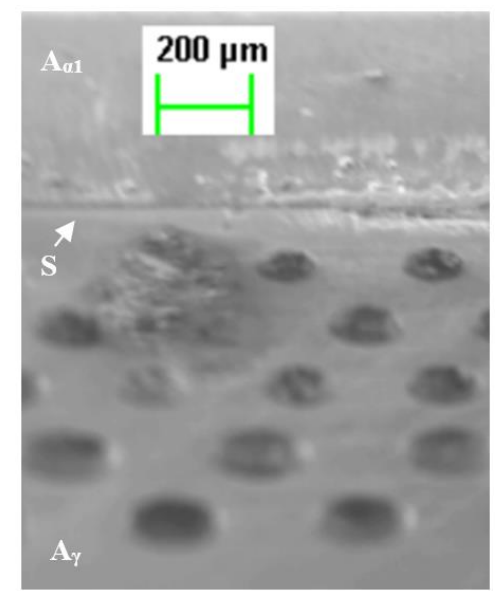

Figure 32. End Mill 4 after $1^{\text {st }}$ measurement.

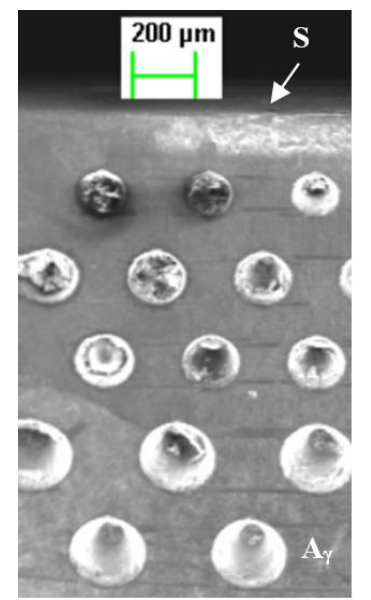

Figure 33. End Mill 4 after $2^{\text {nd }}$ measurement.

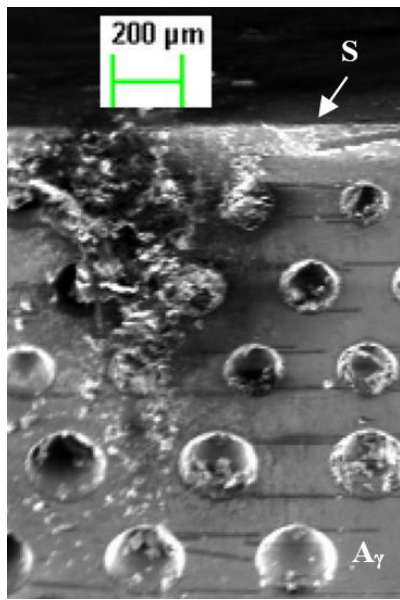

Figure 34. End Mill 4 after 3th measurement.

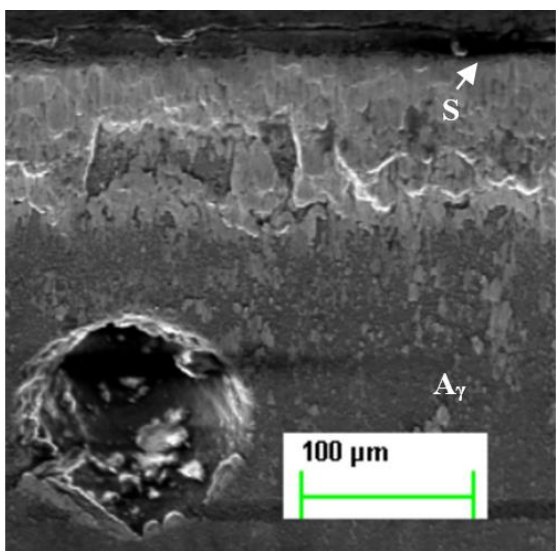

Figure 35. Torn part of the BUE - End Mill 1.

Figure 36. Torn part of the BUE - End Mill 4.

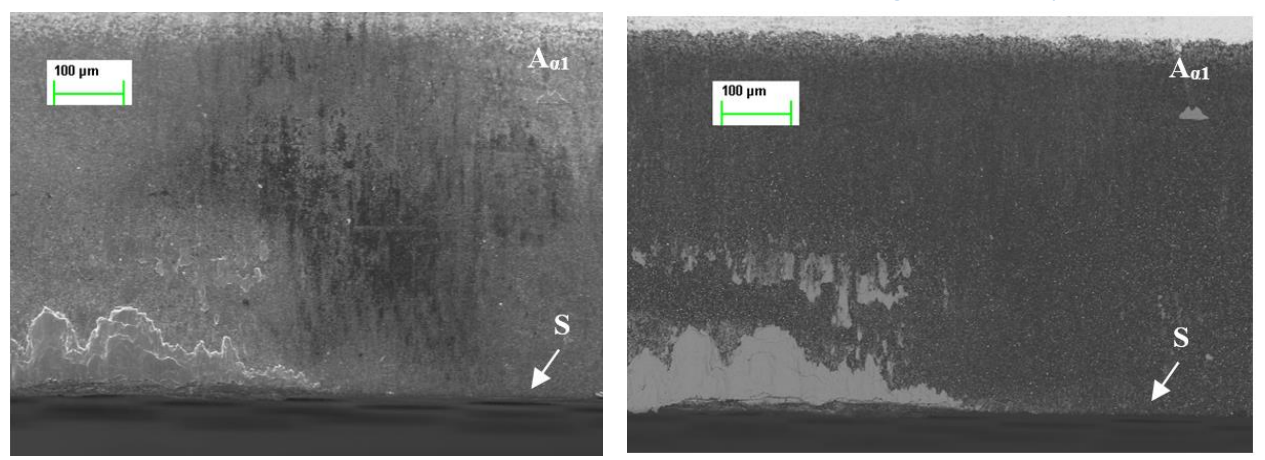

Figure 37. End of the active part of flank face (Secondary Electron Detector). Figure 38. End of the active part of flank face (Backscatter electron detector). 


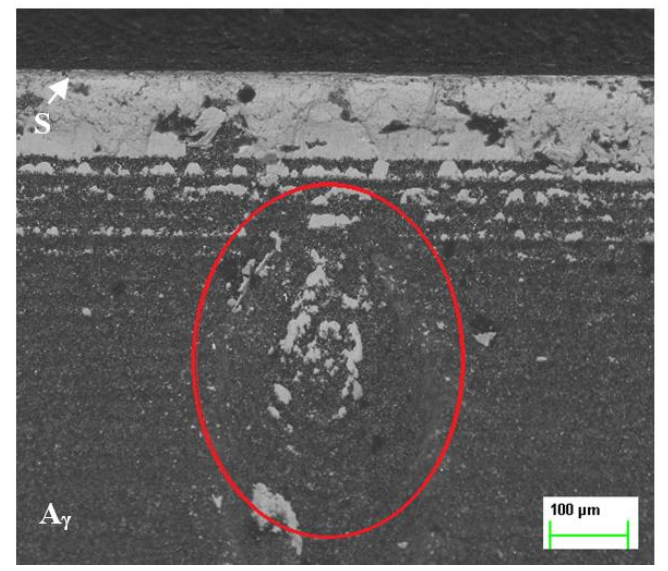

Figure 39. Adhered material on the raised surfaces - End Mill 2.

\section{CONCLUSION}

The design of prototype end mills with chipbreakers was aimed at reducing the interface between the tool and the outgoing chip, achieving a more positive geometry while maintaining the rigidity of the tool and increasing the tool life as well. Experimental dry measurements found that:

- the simple macro modification in the form of holes on the rake face of the insert helped to reduce the cutting forces and the trend of increasing the cutting forces was lower than that of the insert without this modification.

- due to the more positive geometry but also the lower interface between the tool and the chip, integral chipbreakers achieved lower force loading of tool.

- the cutting forces of the end mills with chipbreakers (positive geometry) remained constant throughout the whole experiment, thus longer tool life is expected than for milling cutters without chipbreakers (less positive geometry).

- more positive geometry of tool increased the trend of the Ra value in the feed direction, in other words higher cutting force meant lower Ra. This could be due to the smoothing of the machined surface by chips formed during down milling. This was also indicated by the hardness of the machined surface, where in all cases the higher cutting force meant an increase in the HV of the machined surface. Machined surface was more formed by the chip or deformation process during chip formation. Another explanation could be increasing of rounded cutting-edge radius due to the adherence of workpiece material, which was also indicated by the SEM image. Workpiece material adhered onto tool $\mathbf{1}$ and $\mathbf{4}$ significantly more than in case of end mills with integral chipbreaker.

- adhered layer in the form of a BUE was continuously forming and disappearing. It was torn off after reaching a certain limit.

- in the active part of the chipbreaker 4 , the holes were not sealed with the workpiece material.

- precision of the production of chipbreakers by laser has an impact on the force loading.

- adhesion and flank wear on the end of active part of cutting edge were dominant wear mechanisms under the cutting conditions investigated.

- the workpiece material adhered to the raised surfaces of the integral chipbreakers, which decreased the interface between the tool and the chip.

All end mill with modified rake face of insert showed encouraging results when dry machining. In wet machining (especially when turning), an even more pronounced reduction of the interface can be assumed, since the cutting fluid can

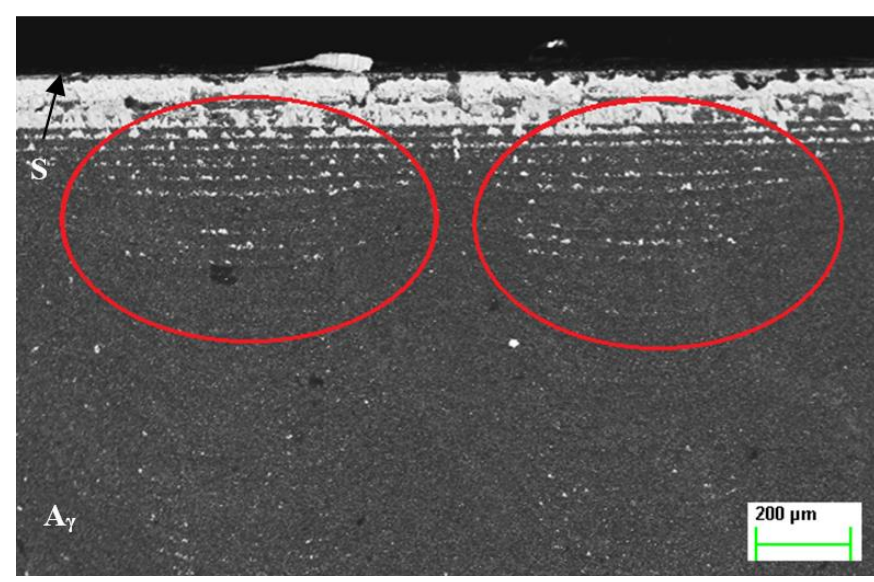

Figure 40. Adhered material on the raised surfaces - End Mill 3.

reach by deeper surfaces up to the cutting edge of the tool (especially tool 3 ). The advantages of holes in the rake face

during wet machining have already been demonstrated [Zeman 2017] and [Rao 2018]. However, it is necessary to go towards an environmentally friendly alternative as in this article.

\section{ACKNOWLEDGMENTS}

This article was supported and co-financed from a specific research FCH/FSI-J-18-5404 called "Research of cutting tools with polycrystalline diamond active part".

\section{REFERENCES}

[Amin 2007] Amin, A.K.M.N., Ismail, A.F. and Khairusshima, M.K.N. Effectiveness of uncoated WC-Co and PCD inserts in end milling of titanium alloy-Ti-6Al-4V. Journal of Materials Processing Technology, October 2007, Vol.192-193, pp 147-158. ISSN 0924-0136.

[Babik 2017] Babik, O., Czan, A., Holubjak, J., Kamenik, R. and Pilc, J. Identification of Surface Characteristics Created by Miniature Machining of Dental Implants Made of Titanium Based Materials. Procedia Engineering, 2017, Vol.192, pp 10161021. ISSN 1877-7058.

[Balazic 2007] Balazic, M. and Kopac, J. Improvements of medical implants based on modern materials and new technologies. Journal of Achievements in Materials and Manufacturing Engineering, December 2007, Vol.25, No.2., pp 31-34. ISSN 1734-8412.

[B. da Silva 2013] B. da Silva, R., Machado, Á.R., Ezugwu, E.O., Bonney, J. and Sales, W.F. Tool life and wear mechanisms in high speed machining of Ti-6Al-4V alloy with PCD tools under various coolant pressures. Journal of Materials Processing Technology, August 2013, Vol.213, No.8., pp 1459-1464. ISSN 0924-0136.

[Brecher 2014] Brecher, Ch., Emonts, M., Hermani, J.-P. and Storms, T. Laser Roughing of PCD. Physics Procedia, 2014, Vol.56, pp 1107-1114. ISSN 1875-3892.

[Corduan 2003] Corduan, N., Himbart, T., Poulachon, G., Dessoly, M., Lambertin, M., Vigneau, J. and Payoux, B. Wear Mechanisms of New Tool Materials for Ti-6Al-4V High Performance Machining. CIRP Annals, 2003, Vol.52, No.1., pp 73-76. ISSN 0007-8506.

[Dumitru 2005] Dumitru, G., Lüscher, B., Krack, M., Bruneau, S., Hermann, J. and Gerbig, Y. Laser processing of hardmetals: Physical basics and applications. International Journal of 
Refractory Metals and Hard Materials, July-November 2005, Vol.23, No.4-6., pp 278-286. ISSN 0263-4368.

[Elementsix 2016] ElementSix. Precision Machining - Giving toolmakers a competitive edge - With PCD, PCBN, CVD diamond \& Single Crystal Diamond. Elementsix. c2016.

[Ezugwu 2003] Ezugwu, E.O., Bonney, J. and Yamane, Y. An overview of the machinability of aeroengine alloys. Journal of Materials Processing Technology, March 2003, Vol.134, No.2., pp 233-253. ISSN 0924-0136.

[Ezugwu 2005] Ezugwu, E. O. Key improvements in the machining of difficult-to-cut aerospace superalloys. International Journal of Machine Tools and Manufacture, October 2005, Vol.45, No.12-17., pp 1353-1367. ISSN 08906955.

[Ezugwu 2007] Ezugwu, E.O., Bonney, J., Da Silva, R.B. and Çakir, O. Surface integrity of finished turned Ti-6Al-4V alloy with PCD tools using conventional and high pressure coolant supplies. International Journal of Machine Tools and Manufacture, May 2007, Vol.47, No.6., pp 884-891. ISSN 08906955.

[Ginta 2009] Ginta, L.T., Lajis, M.A. and Amin, A.K.M.N. The Performance of Uncoated Tungsten Carbide Insert in End Milling Titanium Alloy Ti-6Al 4V through Work Piece Preheating. American Journal of Engineering and Applied Sciences, 2009, Vol.2, pp 147-153. ISSN 1941-7020.

[Haiying 2017] Haiying, X., Wei, Z., Kai, F. and Pengfei, F. TC4 Titanium Alloy Microstructure and Properties Influenced by High Frequency Scan of Electron Beam. Rare Metal Materials and Engineering, June 2017, Vol.46, No.6., pp 1457-1462. ISSN 1875-5372.

[Ji 2015] Ji, W., Liu, X., Wang, L. and Sun, S. Experimental evaluation of polycrystalline diamond (PCD) tool geometries at high feed rate in milling of titanium alloy TC11. The International Journal of Advanced Manufacturing Technology, April 2015, Vol.77, No.9-12., pp 1549-1555. ISSN 0268-3768.

[Kuljanic 1998] Kuljanic, E., Fioretti, M., Beltrame, L. and Miani, F. Milling Titanium Compressor Blades with PCD Cutter. CIRP Annals, 1998, Vol.47, No.1., pp 61-64. ISSN 0007-8506.

[Krishnaraj 2014] Krishnaraj, V., Samsudeensadham, S., Sindhumathi, R. and Kuppan, P. A study on High Speed End Milling of Titanium Alloy. Procedia Engineering, 2014, Vol.97, pp 251-257. ISSN 1877-7058.

[Li 2013] Li, A., Zhao, J., Dong, Y., Wang, D. and Chen, X. Surface Integrity of High-speed Face Milled Ti-6Al-4V Alloy with PCD Tools. Machining Science and Technology, 2013, Vol.17, pp 464482. ISSN 1532-2483.
[Moussaoui 2015] Moussaoui, K., Mousseigne, M., Senatore, J., Chieragatti, R. and Lamesle, P. Influence of Milling on the Fatigue Lifetime of a Ti6Al4V Titanium Alloy. Metals, 2015, Vol.5, pp 1148-1162. ISSN 2075-4701.

[Nabhani 2001] Nabhani, F. Machining of aerospace titanium alloys. Robotics and Computer-Integrated Manufacturing, February 2001, Vol.17, No.1-2., pp 99-106. ISSN 0736-5845.

[Oosthuizen 2011] Oosthuizen, G.A., Akdogan, G. and Treurnicht, N. The performance of PCD tools in high-speed milling of Ti6Al4V. The International Journal of Advanced Manufacturing Technology, February 2011, Vol.52, No.9-12., pp 929-935. ISSN 0268-3768.

[Pittalà 2018] Pittalà, G.M. A study of the effect of $\mathrm{CO}_{2}$ cryogenic coolant in end milling of Ti-6Al-4V. Procedia CIRP, 2018, Vol.77, pp 445-448. ISSN 2212-8271.

[Piska 2016] Piska, M., Trubacova, P., Hornikova, J., Sandera, P. and Boivie, K. A Study of Selective Laser Melting Technology on the Ultra-High Strength Tool Steel Use-Quality, Mechanical Properties and Fatigue. Applied Mechanics, Behavior of Materials, and Engineering Systems, 2016, pp 67-86. ISBN 9783-319-41468-3.

[Pramanik 2014] Pramanik, A. Problems and solutions in machining of titanium alloys. International Journal of Advanced Manufacturing Technology, February 2014, Vol.70, No.5-8., pp 919-928. ISSN 0268-3768.

[Rao 2018] Rao, Ch.M., Rao, S.S. and Herbert, M.A. Influence of Modified Cutting Inserts in Machining of Ti-6Al-4V Alloy Using PCD Insert. Materials Today: Proceedings, 2018, Vol.5, No.9., pp 18426-18432. ISSN 2214-7853

[Safari 2014] Safari, H., Sharif. S. and Izman S. Influence of Cutting Conditions on Surface and Sub-Surface Quality of High Speed Dry End Milling Ti-6Al-4V. Jurnal Teknologi, 2014, Vol.67, pp 131-135. ISSN 2180-3722.

[Shokrani 2012] Shokrani, A., Dhokia, V. and Newman, S.T. Environmentally conscious machining of difficult-to-machine materials with regard to cutting fluids. International Journal of Machine Tools and Manufacture, June 2012, Vol.57, pp 83-101. ISSN 0890-6955.

[Su 2012] Su, H., Liu, P., Fu, Y. and Xu, J. Tool Life and Surface Integrity in High-speed Milling of Titanium Alloy TA15 with PCD/PCBN Tools. Chinese Journal of Aeronautics, October 2012, Vol. 25, No. 5, pp 784-790. ISSN 1000-9361.

[Zeman 2017] Zeman, P. Research of progressive laser technologies (in Czech). MM Prumyslove spektrum, September 2017, Vol.9, pp 54. ISSN 1212-2572.

\section{CONTACT:}

Ing. Tomas Trcka

Brno University of Technology,

Faculty of Mechanical Engineering,

Institute of Manufacturing Technology,

Technicka 2896/2, 61669 Brno, Czech Republic

e-mail: 153306@vutbr.cz 